\title{
An Introduction to Formal Standardization and the Work on ICT Standardization in ISO/IEC - JTC1
}

\author{
Niels Madelung and Katrine Bergh Andersen \\ Chief consultant in Danish Standards and engaged in JTC1 \\ Consultant for research in Danish Standards \\ Received 22 March 2013; Accepted 14 May 2013

\begin{abstract}
The purpose of this article is (a) to give the reader an introduction to formal standardization and (b) an overview of international standardization activities in the field of ICT.

In the first part of the article the introduction to formal standardization will be exemplified at a national level by the national Danish standardization organization (DS), at a European level by the European standardization organizations (CEN/CELENEC and ETSI) and at a global level by the international standardization organizations (ISO, IEC and ITU).

The second part of the article will provide the reader with an overview of the standards and ongoing standardization activities in JTC1 - the joint technical committee between ISO and IEC on ICT standardization. This paragraph will include a number of illustrative examples to give an in-depth impression of the work in the joint technical committee.
\end{abstract}

Keywords: Standardization, standards, ICT, standardization organizations, ISO/IEC JTC1, benefit from standards.

\section{Introduction}

What is a standard? Comparing different sources on the definition of the word "standard", a common understanding is "Universally or widely accepted,

Journal of ICT Standardization, Vol. 1, 1-24.

doi: 10.13052/jicts2245-800X .121

(C) 2013 River Publishers. All rights reserved. 
agreed upon, or established means of determining what something should be".

So in other words a standard needs to be established under conditions where all relevant stakeholders are involved or heard during the establishment of the standard, to insure a successful widely acceptance of the final standard.

In some cases and for a number of reasons (within ICT e.g. timeliness or limited importance or relevance), it is not feasible to aim for a widely accepted standard.

The catch $22^{1}$ of 1 ) wide acceptance versus 2) swift results is in the ICT area often solved by a number of possible standards are developed rather swiftly within narrow selection of stakeholders, such as IT developing companies, and later based on (part of) such standard(s), a larger group or participants of stakeholder representatives, considers and adopt parts of such industry or commercial developed standards, into more widely accepted standards.

In other words industry or commercial developed standards are often the start of a food chain resulting into "Universally or widely accepted, agreed upon, or established means of determining what something should be".

But do we need that standards are universally or widely accepted? Not in all cases, but generally at some stage in most.

Past examples such as BETA versus VHS video tapes, resulted in a list of negative consequences for all stakeholders. The developing companies, production companies, reseller and consumers did all suffer, in terms of unnecessary time and money spend in developing, marketing and buying "the lesser desired alternative".

A more recent example is the standard for universal chargers for dataenabled mobile phones. Again millions of stakeholders have lost time and money - including the negative impact on environment.

In recent years IT developing companies have on their side involved larger and more brought representative groups of stakeholder, earlier in the industrial development of standards as well as the standardization organization e.g. ISO $^{2}$ and $\mathrm{CEN}^{3}$, has changed the developing process of standards, to limit the timeframe for developing widely accepted standards.

1 "Catch 22" - a dilemma or difficult circumstance from which there is no escape because of mutually conflicting or dependent conditions. (Oxford Dictionaries).

2 The International Standardization Organization.

3 The European Committee for Standardization. 


\section{PART 1 - What is formal standardization? And how does it work?}

In the next paragraphs we will start by explaining formal standardization and the essential characteristics of formal standardization. After that we will introduce the different standardization organizations in relation to the organizational level they represent. The standardization organizations can by organized after the area/region they cover: international standardization organizations (e.g. ISO - the International Standardization Organization, IEC - the International Electrotechnical Commission and ITU - the International Telecommunication Union), regional standardization organizations (e.g. the European standardization organizations, CEN - the European Committee for Standardization, CENELEC - the European Committee for Electrotechnical Standardization and ETSI - the European Telecommunications Standards Institute) and last but not least the national standardization organizations (e.g. DS - Danish Standards and BSI - the British Standards Institution).

Thereafter we will try to answer the question Why are standards relevant? by looking at the different benefits from using standards and from participating in the standardization process. Finally we have included a case from RFID (Radio Frequency Identification) standardization to show how interested parties can influence the international standardization process via their national standardization organization.

\subsection{Formal Standardization}

What is a formal standard? And what are the advantages? There are a lot of different definitions of standard and the term is used in a lot of different contexts. Basically you distinguish between private de facto standards and formal de jure standards. De facto standards are developed by one or more company and become standards in the extent they are used by the players in the market. Formal standards are developed in standardization organizations with formal processes for the development and approval. The formal definition of a standard is:

A document established by consensus and approved by a recognized body, that provides, for common and repeated use, rules, guidelines or characteristics for activities or their results, aimed at the achievement of the optimum degree of order in a given context. (DS/EN 45020) 
The formal standards have a number of essential characteristics:

Consensus: Standards are developed in a consensus process which means that the process is open and accessible for all parties interested, and all interest are attempted met through agreement. Standards are in other words not necessarily an expression of the highest expertise or the highest requirements but rather an expression of what the parties involved could agree upon.

Voluntariness: The standardization organizations publish the standards, but they are voluntary to use and the standardization organizations are not obligated to control whether the standards are used correctly. It is therefore crucial for the use of the standards that they are considered relevant by the users - a relevance that often is established in this consensus process.

Contractual basic: Standards are widely used as part of the contractual basic in for example tenders or other contracts. This means that standards frequently become market requirements and from that point on are not experienced as voluntary. This is also the case when standards are mentioned in the law e.g. in directives from the European Commission.

There are a number of different types of standards each with different purposes:

- Terminology standards, which determine terms in different areas in order to make people "speak the same language"

- Product standards, which describe specifications, requirement to functionality or safety for a product

- Test standards, which determine how you test a product in accordance with requirements to functionality

- Standards for measurement, which specify how you measure e.g. concentration of toxic substances in water or in the air.

- Management standards, which are used to control organizations or companies in regard to quality, environmental management, energy performance etc. They are typically used as a basic for certification.

It is not always possible or necessary to make a formal standard. Therefore the standardization organizations have developed other types of documents a kind of preliminary standard. This is for example "technical specifications" and "international workshop agreements". Another example is a "guideline" which is sometimes made to support a standard - e.g. if the content is very difficult or if there are several ways to interpret a standard a guideline might be handy. 
Sometimes the standardization process takes too long for a fast moving industry or product development. These other formal documents can also be a "fast track" to a standard by shortening the standardization process and making the requirements/test method/etc. faster available for the users.

\subsubsection{The Standardization Process}

The standardization process is characterized by formal processes for the development and approval of standards. In short it is summarized in figure 1 below for an ISO standard. The process is very similar in other formal standardization organizations with few exceptions.

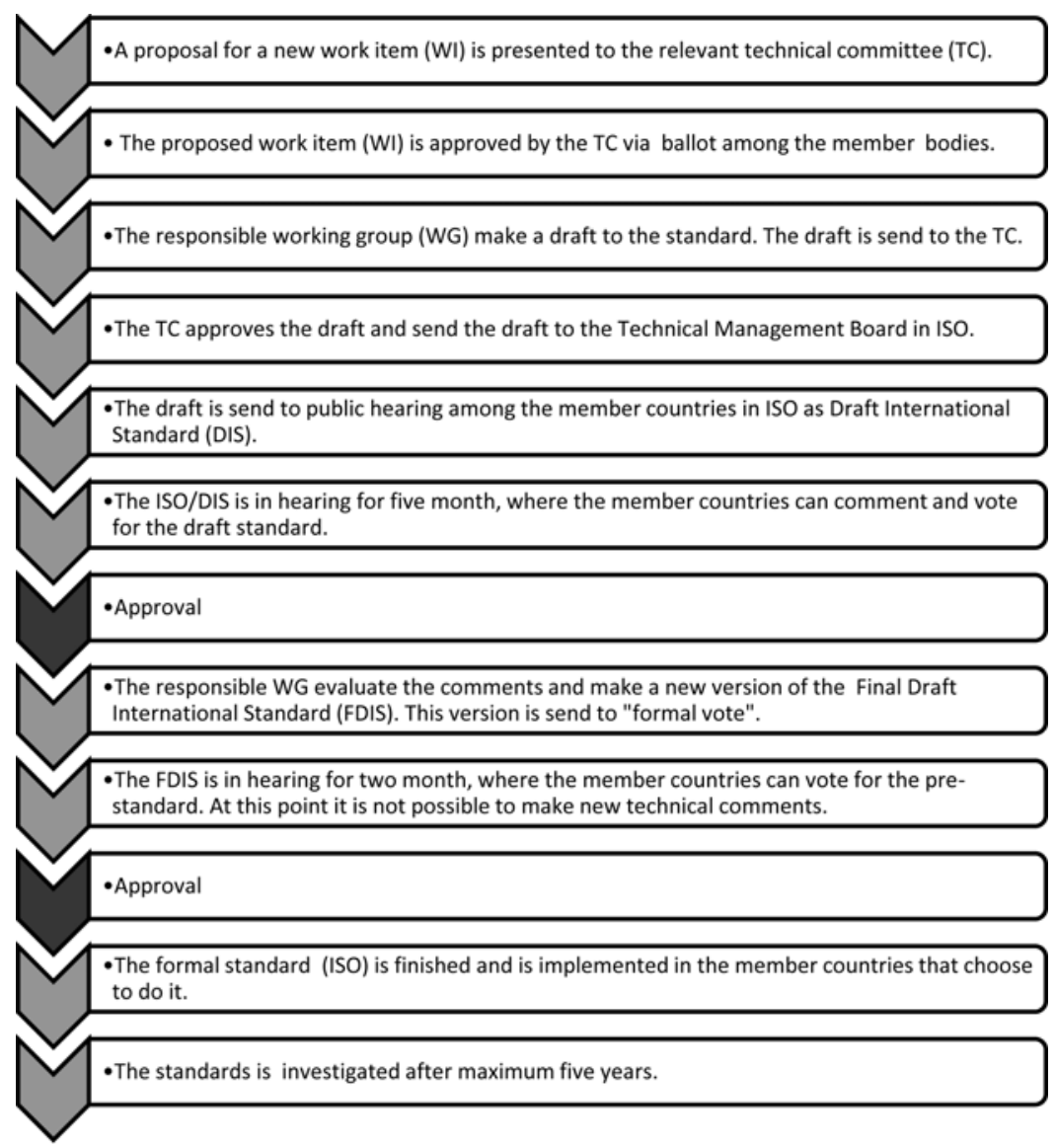

Figure 1 The development of an ISO standard. 


\subsection{International Standardization: ISO, IEC and ITU}

In popular terms standardization is said to be the largest network in the world with around 100.000 members in $\mathrm{ISO}^{4}$ even more if we include the members in IEC $^{5}$ and ITU ${ }^{6}$. Standardization is a continuous everyday activity - actually an average of eight technical meetings in ISO takes place every working day.

ISO and IEC are similar in a lot of ways. IEC covers the electrotechnical standardization and ISO roughly the rest. ISO and IEC are member organizations with one member organization from each member country. Danish Standards is the national Danish member of ISO and IEC - Danish companies, organizations, research institutions, government etc. that wants to participate in the work in ISO or IEC needs to be member of Danish Standards. 163 countries are member of ISO and 82 of IEC - all these countries are represented by a national standardization body - e.g. British Standards Institute in United Kingdom.

ITU differs from ISO and IEC in some ways. It is United Nations specialized agency for information and communication technologies. Being a UN-agency ITU is managed by a different set of rules than ISO and IEC. For example it is possible for a company, organization or research institution to be member of ITU directly - without being member of the national standardization body.

You can read more about the specific organizations on their web pages:

- www.iso.org

- www.iec.ch

- www.itu.org

\subsection{European Standardization: CEN/CENELEC and ETSI}

Besides the international level standardization can also be organized within regions e.g. Europe or the Northern countries/Scandinavia. In this section we will focus on the European standardization organizations; CEN (the European Committee for Standardization), CENELEC (the European Committee for Electrotechnical Standardization) and ETSI (the European Telecommunications Standards Institute).

CEN corresponds to ISO at international level, where CENELEC corresponds to IEC and ETSI to ITU.

\footnotetext{
4 International Standardization Organization.

5 International Electrotechnical Commission.

6 International Telecommunication Union.
} 
CEN is responsible for all formal standardization in Europe except for the electrotechnical (CENELEC) and telecommunication (ETSI). CEN was funded back in 1961 as the first European standardization organization. Today CEN has 33 member countries which make the number of participating countries bigger than in the European Union.

For further information see www.cen.eu.

CENELEC is responsible for the formal electrotechnical standardization in Europe. As CEN, CENELEC has 33 member countries within Europe.

For further information see www.cenelec.eu.

Together CEN and CENELEC have around 13.000 published standards (EN-standards) even more if you count related documents like technical specifications etc.

ETSI was established in 1988 by CEPT (European Conference of Postal and Telecommunication Administrations) on the basis of a proposal from the European Commission that recommended the funding of an organization with responsibility for the establishing of common European standards telecommunication. Today ETSI is responsible for the standardization of information and communications technologies.

\section{Influence/membership of the European standardization organizations}

Danish Standards is the national member of CEN, CENELEC and ETSI for Denmark. Danish Standards is therefore responsible for representing the Danish interests in the three organizations and for providing Danish companies, NGO's, authorities and other interested parties access to the standardization work in the three organizations.

There is a little but very essential difference between CEN/CENELEC and ETSI regarding membership. In CEN and CENELEC a company or another interested party can only be member/participate in the standardization process through membership of a national standardization organization - e.g. Danish Standards. In ETSI it is also possible for a company or another interested party to participate through a national standardization organization, but in ETSI it is also possible for a company or another interested party to be member directly by paying an annual fee. For further information see www.etsi.org.

\subsubsection{The Link Between the European Organizations}

The collaboration between the European standardization organizations are very strong, they have a lot of joint working groups on different transverse 
subjects e.g. education about standardization and engaging SMEs. The collaboration between CEN and CENELEC are particularly strong and they decided in 2010 to establish a common management centre-CEN-CENELEC Management Centre (CCMC) in Brussels.

See www.cencenelec.eu for further information.

All member countries in CEN/CENELEC are obliged to implement all published standards (EN-standards) as national standards and to withdraw any conflicting national standards (if any). This is defined in the internal regulation in CEN/CENELEC. This principle strengthen the European standardization by establishing a common ground and is therefore of high importance.

\subsection{National Standardization: Danish Standards}

Last but not least we have the national level in standardization - it is here that all the companies, experts, researchers etc. are member and get their influence (except with ITU and ETSI see previous paragraphs).

Almost every country in the world has a formal national standardization body - some countries even have two because they have a separate body to handle the electrotechnical standardization. In figure 2 below your find an illustration of the extension of standardization worldwide exemplified in a map of $\mathrm{ISO}^{7}$ member countries.

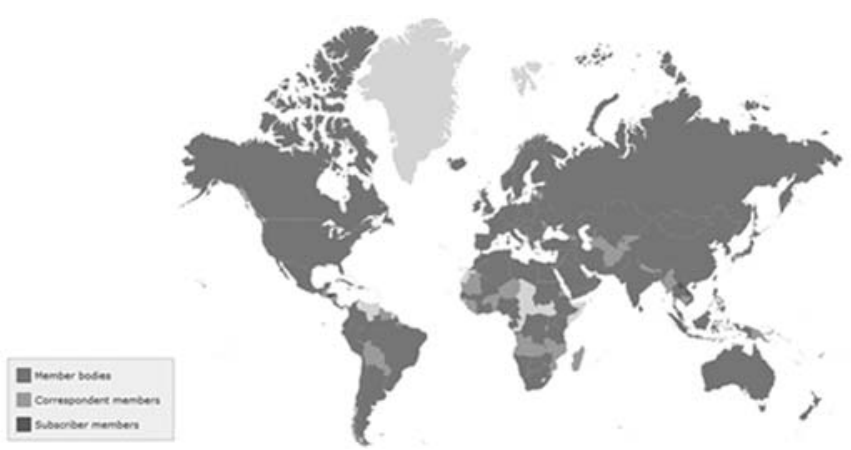

Figure 2 All the gray countries have a formal standardization body ${ }^{7}$. (The different tones of gray indicate the status of their membership in ISO.)

7 Greenland does not have a formal national standardization body - in practice they have a close cooperation with Danish Standards to ensure the use of standards in Greenland and Greenland's interests. 
Danish Standards is the formal standardization body in Denmark. We are therefore responsible for the formal standardization in Denmark and for representing the Danish interest in European and international standardization - we are therefore the national member of ISO, IEC, CEN, CENELEC and ETSI. Danish Standards is not member of ITU - here Denmark is represented by the national authorities.

Danish Standards has around 220 technical committees spread over the areas where we have interested stakeholders in Denmark. There are almost 2000 members of our technical committees from around 850 different companies.

Danish Standards is also responsible for the Danish WTO ${ }^{8}$ Enquiry Point. We answer 4000 to 5000 enquiries every year from Danish and foreign companies and organizations about standards and trade with Denmark.

\subsection{Why Standards?}

A very important and relevant question to ask at this point is WHY standards/standardization? What are the benefits? In the following sections we will specify the benefits from using standards or participating in the standardization process for different segments.

The general philosophy behind standardization is to make life easier for the users of the standards by making it easier to specify e.g. requirements to a product (they are specified in the standard) and by making it easier for the company to document that they fulfil the requirements. This is done by establishing a common ground in the standards for e.g. test requirements or quality management. Depending on the standard a company using a standard makes sure that their product or service is compatible with other products and meets the requirements in the law (e.g. the use of harmonised standards regarding CE-marking in the European Union).

Standards also enhance market maturity and can be used to enter new markets to develop growth. This is relevant because a standard can help maturing a technology to be ready for the market. This is mainly the case with new standardization topics.

When participating in standardization you basically get three things: knowledge, influence and network.

Knowledge of the upcoming standards and the underlying rationales.

Influence on the upcoming standards and the requirements in them.

\footnotetext{
8 World Trade Organization.
} 
Network with the other participants, often from different positions in the society than yourself and from around the world. In popular terms standardization is said to be the biggest network in the world. This network will also contribute to your company or organization by providing knowledge and influence to e.g. the product development.

\subsubsection{A Society Point of View}

Looking at the benefits from a society point of view the following benefits can be mentioned. Standards:

- are a catalyst for growth

- increase international trade (by reducing trade barriers and making the transition of goods between companies/markets easier)

- utilize the expert knowledge in society/industry and best practices - to make the knowledge accessible for companies and society in general

- enhance the innovation in the companies - by setting new standards they need to improve/develop

- define a base for developing and implementing new technologies/knowledge - e.g. smart-grid and electrical cars.

\subsubsection{A Company Point of View}

Besides the previous mentioned benefits which of course also apply for companies, standards are a highly efficient means to inject market knowledge directly into the company's product development, service design, and other innovative processes. It is also relevant the other way around - companies can use standards to disseminate knowledge to the market in order to make their way "the way".

Standards can also be used to give directions/requirements to a subcontractor in order to improve the probability for receiving the desired product - maybe to ensure compatibility with existing products or components. It is much easier for a company to refer to a standard with requirements than to formulate the requirements from time to time. Making their own requirements also enhances the probability for misunderstandings. When using a formal standard it is more likely to avoid misunderstandings and misinterpretations because of the dissemination and accept of formal standards. For start-up companies, and for any company that wants to launch a new product in a given market, it is a major advantage that they know how to use and benefit from the system of standardization. 
Standards are often key to market access - they help ensure compatibility, safety, and compliance with regulatory and market demands. In other words standards minimize the time-to-market for new inventions because they can be used to pave the way by removing barriers. Standards are also known for minimizing the costs in intra-Community trade.

Standards can literally make or break the successful commercialization of a new idea. An example of this could be a company that has developed a new product for the market (e.g. a piece of electrical equipment). First when the product is fully developed and ready to go to the market the company finds out that the product needs to be CE-marked. To CE-mark electrical equipment the product needs to fulfil the requirements in the relevant European directive (2006/95/EC) and the relevant harmonised standards. If the product does not fulfil the requirements in the harmonised standards and has not been tested after the standardized test methods, the product is considered to be illegal and the product development process needs to start over - now taking the relevant standards into account. Not knowing the right standards can, especially for a small company, mean the difference between bankruptcy and success.

An analysis from DAMVAD (a northern consultancy bureau) made for The Danish Business Authority published in 2013 have looked at the value creation of standards in the companies using them. Companies most often use/implement standards because of a demand from the market or a requirement in the law, but the analysis shows that they also experience unexpected or other benefits:

- $77 \%$ of the companies in the analysis experience that standards enhance the quality of their product

- $80 \%$ of the companies experience that standards contribute with new knowledge

- $60 \%$ experience that the co-operation with subcontractors and customers become more simple

- $72 \%$ experience that implementing standards increase the confidence from the customers.

\subsubsection{A Research Point of View}

The last perspective we will look at regarding benefits from using standards and participating in standardization is from a research point of view. The focus on using standards in connection with dissemination of research results are increasing, especially in Europe where the focus on dissemination research results to get funding from the European framework programmes (FP7 and 
Horizon2020) are getting stronger. According to the newest draft version of Horizon2020 standardization will be mentioned in Horizon $2020^{9}$ as an aspect to consider in the dissemination phase. Therefore applications including standardization will be more likely to get funding.

The focus on using standards as dissemination of research results come from the importance for the society, the industry, growth and employment that the result from research projects are communicated and made available for the public. Standardization is one way of ensuring this - and is getting increasingly more widespread. Standard open up the knowledge and is making the knowledge available to all interested parties in contrast to e.g. patenting and academic articles (often for a limited audience).

\subsubsection{A Political Push for ICT Standardization}

Standardization has different impact in different areas - some of it is linked to the spreading and number of standards with in the area. The above-mentioned benefits from standards and standardization more or less also apply for ICTstandardization. Very relevant for the ICT area is the maturing of markets and technologies at the same time. This convergence lead to a more constant development and the companies therefore get a longer period for investment - this again increases the investments and creates a basis for research and development activities, which increases the competitiveness.

To zoom on the European level there are an increasingly focus on the necessity for standardization within ICT. This is for example something The European Commission's recognizes the importance of in their 2020-strategy:

"At EU level, the Commission will work:

-...

- To reform the research and innovation funds and increase support in the field of ICTs so as to reinforce Europe's technology strength in key strategic fields and create the conditions for high growth SMEs to lead emerging markets and to stimulate ICT innovation across all business sectors;"

(Europe 2020 - A European strategy for smart, sustainable and inclusive growth, EC, Communication from the Commission, 2010)

\footnotetext{
9 When writing this article Horizon2020 was not finally approved but still for negotiation in the European Commission.
} 
This is also reflected in a new regulation from the European Parliament on European Standardization, where it is made clear, that ICT standardization is a priority (Chapter IV).

Therefore standardization with ICT is an important focus area in the relevant standardization organizations these years.

\subsection{From a National to an International Standard - a Case of the RFID Chip}

It might seem to be very difficult to influence the development of international standards - but that is not the case. As this case will illustrate you just need to be strategic, willing to negotiate and aware of the political game in standardization.

The following case is based on an interview with Carsten Riis Fredriksen, standardization consultant in Danish Standards and working with RFID ${ }^{10}$ standardization.

\subsubsection{Development if "The Danish Data Model"}

In the beginning of the twenty-first centuries The Danish Agency for Culture decided that they wanted a standard for RFID microchips for the libraries. In cooperation with Danish Standards a national committee was established. From the beginning a lot of different partners were involved, Danish as well as international, because The Danish Agency for Culture wanted an internationally valid standard. The reason that they wanted an internationally valid standard was to create a platform for the suppliers to deliver the RFID system for the Danish libraries. This would help create a market for RFID chips for libraries and to create a system applicable for all libraries in Denmark. Other countries would benefit from this as well.

In 2005 they succeeded in making a (national Danish) technical information called DS/INF 163, RFID Data Model for Libraries.

\subsubsection{From a National to an International Standard}

From this point on the goal was to obtain international agreement on the standard in order to make an ISO standard. A working group under ISO TC 46/SC 4 Technical interoperability was established and a representative from Denmark became convener for the working group that was to make the standards for RFID in libraries (ISO/TC 46/SC 4/WG 11).

10 Radio Frequency Identification. 
Some countries were against "The Danish Data Model" because it did not fit their national systems. To meet this demands the Danish team came up with the idea of making one overall standard with the general guidelines and to separate parts - one in accordance with The Danish Data Model and one in accordance with the other system. The model with one overall standard and to part for the two different systems made it possible to reach consensus. The three ISO standards compose the ISO 28560-series that were published in 2011.

\subsubsection{The National Situation Today}

When the ISO 28560-series on RFID was approved the national technical information in Denmark - DS/INF 163 - was withdrawn because it had become unnecessary. To make the implementation of the ISO 28560-series easy for the Danish libraries a new technical information was made specifying the specific Danish requirements (DS/INF 28560).

RFID not only used in libraries but in a wide variety of businesses where there is a need for information exchange e.g. traceability of containers or medical equipment. Denmark is also active in other areas of RFID, but it is only in the case of libraries that our influence has been that extensive.

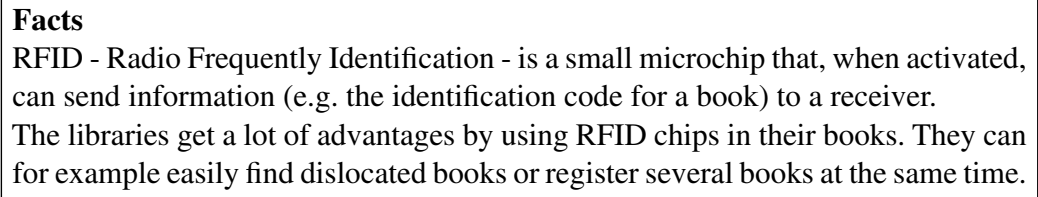

\subsubsection{The Standards}

DS/INF 163 RFID Data Model for Libraries (withdrawn)

DS/ISO 28560-1 Information and documentation - RFID in libraries

- Part 1: Date elements and general guidelines for implementation

DS/ISO 28560-2 Information and documentation - RFID in libraries - Part 2: Encoding of RFID date elements based on rules from ISO/IEC 15962

DS/ISO 28560-3 Information and documentation - RFID in libraries - Part 3: Fixed length encoding

DS/INF $28560 \quad$ RFID in libraries 


\section{PART 2 - A Snapshot of the International Standardization Activities in ICT}

\subsection{The Background}

ISO started its ICT standardization activities in the beginning of 1960, back in the days when a computer should have the size of a small office building to match $5 \%$ of the power of a laptop anno 2013.

ICT took off both from a technical and a user point-of-view. Both ISO and IEC worked hard on keeping up with the increasing demand of standards. By the 1980 'ies computer were everywhere from business, government, schools and private homes.

To keep up the constant increasing demand of standards and to avoid the risk of duplicative or incompatibly standards, ISO and IEC joint forces in the area of ICT in 1987, by joining their respectively technical committees (all together three) into what today is known as the joint technical committee ISO/IEC JTC 1.

In 2012, JTC 1 celebrated 25 years of ICT International Standards development (1987 - 2012). Read "25 years of JTC 1 - We've come a long way!" for more information.

Today, ISO/IEC JTC 1 is one of the largest and most prolific technical committees in international standardization. With over 2.500 published standards under the broad umbrella of the committee and its 19 subcommittees, ISO/IEC JTC 1 makes a huge impact on the ICT industry worldwide.

By 2013 JTC 1 consists of more than 100 working groups, under its 19 subcommittees. It's within the working groups that standards are developed.

The reason for that we in our day-to-day activities can make "sense" out of the characters on our keyboards, create MPEG files, use smartcards and much more, is thanks to the dedicated work of the experts involved in JTC 1 working groups, representing close to half of the countries in the world.

\subsubsection{The Mission and Principles}

\section{Mission}

JTC 1s mission is to develop, maintain, promote and facilitate IT standards required by global markets meeting business and user requirements concerning:

- Design and development of IT systems and tools

- Performance and quality of IT products and systems

- Security of IT systems and information 
- Portability of application programs

- Interoperability of IT products and systems

- Unified tools and environments

- Harmonized IT vocabulary

- User friendly and ergonomically designed user interfaces

\section{Principles}

JTC 1 standards development will be conducted with full attention to a strong business-like approach (e.g., cost effective, short development times, market-oriented results.)

JTC 1 will provide a wide range of quality products and services, within its scope and mission, to cover identified global needs.

The JTC 1 community will actively promote the use of its products and services and the timely implementation of JTC 1 standards within the form of useful products on a worldwide basis.

JTC 1 will ensure that its user needs including multicultural requirements, are fully met, such that its products and services promote international trade.

JTC 1 recognizes the value of the work of other organizations and the contribution they make to international IT standardization and will complement existing and forthcoming JTC 1 programs through other leading edge activity with the objective of providing the best standards worldwide.

JTC 1 will provide a standards development environment which attracts technical experts and users having identified standardization needs.

\subsection{The Structure}

ISO/IEC JTC 1 acts as an umbrella and management board for a number of $\mathrm{SC}$ (sub-committees).

JTC 1 has a chairperson (currently Ms. Karen Higgenbottom, USA) and conduct annual meetings - JTC 1 Plenary meetings - where countries participating in the work of JTC 1's SC participates, receives reports and request from the chairpersons of the individual SC and make decisions in terms of initiating and delegating of work, cancellation of work, establishment and closing of sub-committees etc.

All SC's and WG's conducts there work in cooperation with other standardization organizations (e.g. technology or industry oriented) where relevant, to avoid conflicts or duplication of work.

Much cooperation is long lasting and the exchange of information is formalized by entering into a liaison agreement and by each party appointing 
liaison officers that site-in on the other parties meetings, as well as being included on mailing list etc.

Especially during the last 10 years development and practical use of ICT, the "old" definitions and silos in which we use to divide ICT into has been challenged. E.g. Smart Grid is a good example, since both the power technology, power meters, information security and other ICT aspects goes into that new and growing technology and business area. Other examples on the falling down of silos are Augmented Reality and Cloud Computing, the latter also motivated by the privatisation of the National Telco Companies.

For those reasons the following names (definitions) must be taken with a grain of salt. And for that reason as well the number of liaison partnerships is steadily growing and branching out.

Table 1 JTC 1 working groups and sub-committees with underlying working groups.

\begin{tabular}{ll}
\hline SC/WG & Name and Working Groups \\
\hline SWG 1 & Accessibility \\
AHG 3 & Tools \\
AHG 2 & Structure \\
SWG 3 & Planning \\
SWG 2 & SWG - Directives \\
AHG 1 & Incubator \\
WG 7 & Sensor networks \\
WG & Governance of IT \\
SC 2 & Coded character sets \\
SC 6 & WG 2 Universal coded character sets \\
& Telecommunication and information exchange between systems \\
& WG 1 Physical and data link layers \\
& WG 7 Network, transport and future network \\
SC 7 & WG 8 Directory \\
& WG 9 ASN.1 and registration \\
& Software and systems engineering \\
& SWG 5 Standards management group \\
& SWG 22 Vocabulary validation \\
& AG 13 Life Cycle Processes Harmonization \\
& WG 2 System software documentation \\
& WG 4 Tools and environment \\
& WG 6 Evaluation and metrics \\
& WG 7 Life cycle management \\
& WG 10 Process assessment \\
&
\end{tabular}

11 SWG - Special Working Group.

12 AHG - Ad-Hoc Group.

13 AG - Advisory Group. 
Table 1 Continued

SC/WG Name and Working Groups

WG 19 Open distributed processing and modelling languages

WG 20 Software and systems bodies of knowledge and professionalization

WG 21 Software asset management

WG 23 System quality management

WG 24 SLC Profile and guidelines for VSE

WG 25 IT Service management

WG 26 Software testing

WG 27 IT enabled services

WG 28 Common Industry Formats for Usability Reports

WG 42 Architecture

SC 22 Programming languages, their environments and system software interfaces WG 4 COCOL

WG 5 Fortran

WG 9 Ada

WG 14 C

WG 17 Prolog

WG $21 \mathrm{C}++$

WG 23 Programming Language Vulnerabilities

SC 23 Digital Recorded Media for information interchange and storage WG 6 iVDR Cartridge

WG 7 Joint WG between SC 23, TC 42 and TC171/SC 1

SC 24 Computer graphics, image processing and environmental data representation WG 6 Augmented reality continuum presentation and interchange

WG 7 Image processing and interchange

WG 8 Environmental representation

WG 9 Augmented reality continuum concept and reference model

SC 25 Interconnection of information technology equipment

WG 1 Home electronic systems

WG 3 Customer premises cabling

WG 4 Interconnection of computer systems and attached equipment

SC 27 IT Security techniques

WG 1 Information security management systems

WG 2 Cryptography and security mechanisms

WG 3 Security evaluation, testing and specification

WG 4 Security controls and services

WG 5 Identity management and privacy technologies

SC 28 Office equipment

WG 1 Advisory WG

WG 2 Consumables

WG 3 Productivity

WG 4 Image quality assessment

WG 5 Office Colour 
Table 1 Continued

\begin{tabular}{|c|c|}
\hline$\overline{S C / W G}$ & Name and Working Groups \\
\hline \multirow[t]{3}{*}{ SC 29} & Coding of audio, picture, multimedia and hypermedia information \\
\hline & WG 1 Coding of still pictures \\
\hline & WG 11 Coding of moving pictures and audio \\
\hline \multirow[t]{7}{*}{ SC 31} & Automatic identification and data capture techniques \\
\hline & WG 1 Data carrier \\
\hline & WG 2 Data structure \\
\hline & WG 4 Radio frequency identification for item management \\
\hline & WG 5 Real time locating systems \\
\hline & WG 6 Mobile item identification and management \\
\hline & WG 7 Security for item management \\
\hline \multirow[t]{5}{*}{ SC 32} & Data management and interchange \\
\hline & WG 1 eBusiness \\
\hline & WG 2 MetaData \\
\hline & WG 3 Database language \\
\hline & WG 4 SQL/Multimedia and application packages \\
\hline \multirow[t]{7}{*}{ SC 34} & Document description and processing languages \\
\hline & WG 1 Information description \\
\hline & WG 2 Information presentation \\
\hline & WG 3 Information association \\
\hline & WG 4 Office Open XML \\
\hline & WG 5 Document interoperability \\
\hline & WG 6 OpenDocument Format \\
\hline \multirow[t]{8}{*}{ SC 35} & User interface \\
\hline & WG 1 Keyboards and input interfaces \\
\hline & WG 2 Graphical user interface and interaction \\
\hline & WG 4 User interfaces for mobile devices \\
\hline & WG 5 Cultural and linguistic adaptability \\
\hline & WG 6 User interfaces accessibility \\
\hline & WG 7 User interfaces object, actions and attributes \\
\hline & WG 8 User interfaces for remote interactions \\
\hline \multirow[t]{8}{*}{ SC 36} & Information technology for learning, education and training \\
\hline & WG 1 Vocabulary \\
\hline & WG 2 Collaborative technology \\
\hline & WG 3 Learner information \\
\hline & WG 4 Management and delivery of learning, education and training \\
\hline & WG 5 Quality assurance and descriptive frameworks \\
\hline & WG 6 Platform, Services and Specification Integration \\
\hline & WG 7 ITLET - Culture, language and individual needs \\
\hline \multirow[t]{4}{*}{ SC 37} & Biometrics \\
\hline & WG 1 Harmonized biometric vocabulary \\
\hline & WG 2 Biometric technical interfaces \\
\hline & WG 3 Biometric data interchange formats \\
\hline
\end{tabular}


Table 1 Continued

\begin{tabular}{ll}
\hline $\boldsymbol{S C / W G}$ & Name and Working Groups \\
\hline & WG 4 Biometric functional architecture and related profiles \\
& WG 5 Biometric testing and reporting \\
& WG 6 Cross-Jurisdictional and Social Aspects of Biometrics \\
SC 38 & Distributed application platform and services \\
& WG 1 Web services \\
& WG 2 Service Oriented Architecture (SOA) \\
& WG 3 Cloud Computing \\
SC 39 & Sustainability for and by information technology \\
& WG 1 Resource Efficient Data Centres \\
& WG 2 Green ICT \\
\hline
\end{tabular}

\subsection{The Outcome}

The number of projects on new standards and revision of current ones is very high. In some SC they have a "wish list" of projects that they have to hold back due to the load of current projects. This is also a subject that often is brought up on the JTC 1 Plenaries, where the load of project are tried to be spread out.

The following acts only as examples on what lately has been or is in the process of being produced by the SC under JTC 1 .

Table 2 Current projects under JTC 1

SC ISO/IEC standard number and title (part of)

210646 Revised Universal Character Set

10646 Character for Old Hungarian, Albanian and others

69834 Generation of Universally Unique Identifiers (UUID) 15149 Magnetic field area network (MFAN)

730105 Business Process Outsourcing Lifecycle Processes 42030 Architecture Evaluation 90003 Application of ISO 9001 to computer software

1711694 Use of biometrics on an optical memory card 18745 Physical Test Methods for Passport Books 30117 Guide to on-card biometric comparison standards and appl.

2329121 Data migration method for DVD-R, -RW, -RAM and others

2419775 Extensible 3D (X3D) - Processing (several standards) 19776 Extensible 3D (X3D) - Representation (several standards)

2529104 Management protocol for ubiquitous home network services 29108 Terminology for intelligent homes 29145 Wireless Beacon-enabled Energy Efficient Mesh network 30100 Home network management 
Table 2 Continued

\begin{tabular}{ll}
\hline SC & ISO/IEC standard number and title (part of) \\
\hline 27 & 18370 Blind digital signatures \\
& 20008 Anonymous digital signatures \\
& 24760 Framework for Identity Management \\
& 27001 Information security management systems ${ }^{14}$ \\
& 27016 Organizational economics \\
& 27017 Information security controls for the use of Cloud Computing \\
& 27018 Data protection controls for public cloud computing services \\
& 27035 Information security incident management \\
& 27036 Information security for supplier relationships \\
29101 Privacy architecture framework \\
15444 JPEG 2000 image coding systems Compound image file form. \\
23000 MM appl. Format (MPEG-A) Augmented reality appl. form. \\
15961-2 RFID for item management Registration of RFID data \\
15961-3 RFID for item management RFID data constructs \\
18004 Automatic Id and data capt. tech. QR bar code symb. spec. \\
19763 MFI Core model and basic mapping \\
30114 Extensions of office open XML file format Guidelines \\
35 \\
30109 Worldwide-available personalized computing environment \\
30113 Gesture-based interface across device and methods \\
30122 Principal voice commands Framework and general guidance \\
19788 Learning, education and training Metadata for learning res. \\
19796 Quality for learning, educ., and training Products and Serv. \\
36001 Quality for learning, educ., and training Management Syst. \\
19785 Common Biometric Exchange Formats Framework \\
19794 XML Encoding \\
29196 Guidance for Biometric Enrolment \\
29794 Biometric Sample Quality Standard Iris image \\
30107 Anti-Spoofing and Liveness Detection Techniques \\
17788 Cloud Computing Reference Architecture \\
30132 IT sustainability Guidance for dev. of Energy Efficient ICT \\
30134 Data Centres KPI Power usage effectiveness \\
\hline
\end{tabular}

\section{Conclusion and Perspectives}

The purpose with this article was to introduce formal standardization - its benefits and advantages - plus to give an overview of activities within ICT standardization in ISO/IEC JTC1. The intention was to strengthen the necessity and the benefits from knowing and using formal standardization. The focus on formal standardization is in many contexts increasing and the benefits for companies, society and researchers are getting more explicit. As the devel-

14 As from 2013 all parts of the Danish Government has to comply with this standard. 


\section{N. Madelung and K. Bergh Andersen}

opment is at the moment, standardization will only become more widespread over the next years. We hope this article will provide the reader with a taste of the formal standardization world both in general and within ICT.

The importance of what we today refer to as ICT standardization will go on another $25+$ years. The job has not been done yet and never will. The scene of ICT grows bigger and more interrelated with other part of what we used to see at completely separate issues.

Who ever thought 10 years ago that our electrical power should be connected with ICT, or our legal right of privacy had anything to do with ICT, (mobile) phones or driving and navigating?

The many coming years challenge concerning ICT, will be the interrelated and innovative new ways of conducting our business and private lives local and international.

The good old days where we neatly could separate things under each completely separate label has long gone, and we are now - without knowing it - floating around, look for new labels.

Maybe 5-10 years from now, we will not refer to ICT as common nominator, but will have invented completely new ways of separating logical groups from each other.

But whatever new areas we invent or new labels we will use, standardization will not be less important. On the contrary "Universally or widely accepted, agreed upon, or established means of determining what something should be" will become even more important.

The timeframe of creating standards will play an even important role as well will the agility in revising standards. The gallery of stakeholders will develop; the users will get more directly involved and have a larger impact of what will be "accepted" and what not.

ICT standardization is here to stay, it whatever name, shape or form - that is already universally agreed.

\section{References}

[1] 25 years of ISO/IEC JTC 1 - We've come a long way! http://www.iso.org/iso/home/news_ index/news_archive/news.htm?refid=Ref1601

[2] DS/EN 45020, Standardization and related activities - General vocabulary

[3] DS-hæfte 17, Introduktion til standardisering, Danish Standards, 2012

[4] Europe 2020 - A European strategy for smart, sustainable and inclusive growth, EC, Communication from the Commission, $2010 \mathrm{http} / / / \mathrm{ec}$.europa.eu/eu2020/pdf/ COMPLET\%20EN\%20BARROSO $\% 20 \% 20 \% 20007 \% 20$-\%20Europe $\% 202020 \% 20$ $\% 20 \mathrm{EN} \% 20$ version.pdf 
[5] Jerlang, Jesper, "Standardisering som regulering", Standardisering som regulering - en antologi om standardisering i krydsfeltet mellem politik og marked. DS-hæfte 32, Danish Standards 2012, pp. 13-27.

[6] REGULATION (EU) No 1025/2012 OF THE EUROPEAN PARLIAMENT AND OF THE COUNCIL of 25 October 2012 on European standardisation (Chapter IV) http://eurlex.europa.eu/LexUriServ/LexUriServ.do?uri=OJ:L:2012:316:0012:0033:EN:PDF

[7] Standarder som vardiskaber i danske virksomheder. Report made by DAMVAD for The Danish Business Authority (January 2013)

\section{Biography}

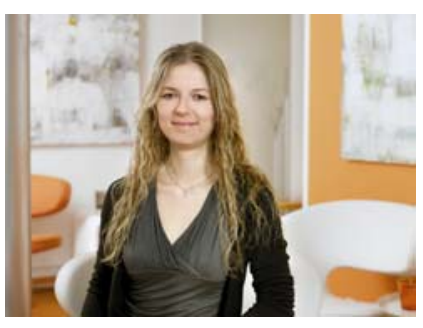

Katrine Bergh Andersen

Consultant for research and education in Danish Standards

Katrine Bergh Andersen is working with strengthening the relation between standardization and research, which she has been doing since 2010. Before that she has been working as information consultant in Danish Standards. She has a master's degree in psychology of language from the University of Copenhagen.

In Danish Standards Katrine is establishing and coordinating research projects in Danish Standards. She is also representing Danish Standards in the European working groups and projects under theauspices of CEN/CENELEC regarding research. At a national level she is managing the national contact point (NCP) for research in standardization.

Danish Standards is the national standardization organisation in Denmark working with formal standardization, and therefore the national member of Danish member of CEN, CENELEC, ISO and IEC.

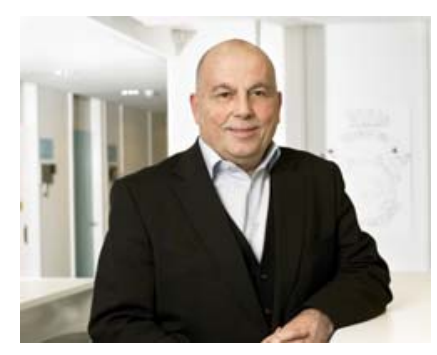

\section{Niels Madelung}

Chief consultant

Niels Madelung is chief consultant at the Consulting Department at Danish Standards. He works with business development in the areas of service and product development, quality management, process optimization, risk management and business continuity.Niels is the author of the Danish book "Glidikkeibananskrællen" about risk management. 
$\mathrm{He}$ is specialized in business and operational improvements, Lean Management, SixSigma (Yellow Belt), Quality Management, Risk Management, Business Continuity and he is an ISO standardization specialist with particular emphasis onISO 9001, ISO 26000, ISO 27001, ISO 27002, ISO 29100 and ISO 31000.

Niels is an expert in ISO/IEC SC 38, Cloud Computing, co-editor on revision of ISO/IEC 27002 Information Security Guideline and cofounder of The Danish Council for Greater IT-security. 